Papathomas, A., \& Lavallee, D. (2006). A life history analysis of a male athlete with an eating disorder. Journal of Loss and Trauma, 11, 143-179.

\begin{abstract}
An exploratory investigation, employing the life history method, was conducted with a male athlete with an eating disorder. The focus of the life history is Mike (pseudonym), an individual with a strong athletic identity, who developed bulimia amidst aspirations to be an elite sports performer. Nine interviews were conducted, and the focus was Mike's athletic career and eating disorder experiences. Interviews were structured around the life course, beginning with early childhood memories and ultimately reaching the present day. In total, 11 hours of life history data were gathered. All interviews were recorded and transcribed. Schlossberg's (1981) model of human adaptation to transition provided a framework to discuss critical life transitions or epiphanies. As a perfectionist, eager to please adolescent, Mike was at high-risk for eating disorder development. His narrative suggests the achievement threats and weight-based performance pressures associated with elite competitive sport played a role in precipitating the onset of bulimia nervosa. When such performance pressures were removed the eating disorder remained and evolved, suggesting that disordered eating in sport can have deeper roots as opposed to being primarily situational. Recovery coincided with the cessation of sport participation and the opening up of a foreclosed identity.
\end{abstract}




\section{A Life History Analysis of a Male Athlete with an Eating Disorder}

An eating disorder may be defined as a "persistent disturbance of eating or eating-related behavior that results in the altered consumption or absorption of food and that significantly impairs physical health and/or psychosocial functioning” (Fairburn \& Walsh, 1995, p. 135). At their most extreme, eating disorders can lead to death. Standardized mortality rates, when compared to the general population matched for age, sex and study duration, show that for people with anorexia nervosa mortality can be up to six times that in the general population (Crisp, Callender, Halek, \& Hsu, 1992; Sullivan, 1995). Mortality in bulimia nervosa is less prevalent due to the absence of severe weight loss and associated medical risks (Goldbloom \& Kennedy, 1995). The psychological disturbance with bulimia can, however, be devastating and research reports have identified cases of suicide in traced cohorts (Maddocks, Kaplan, Woodside, Langdon \& Piran, 1992; Mitchell et al., 1988).

People with bulimia and anorexia endure a wide range of physical sicknesses. Those who have anorexia are prone to osteoporosis resulting in stunted growth and bone fractures (Rigotti, Neer, Skates, Herzog, \& Nussbaum, 1991). Cardiac abnormalities, particularly bradycardia, have been shown to be present in up to $87 \%$ of patients (Fohlin, 1977). Endocrine (e.g., presence of amenorrhea), gastrointestinal, renal, and haematological complications are also common comorbidities (Sharp \& Freeman, 1993). Medical concerns for people with bulimia include erosion of dental enamel due to persistent vomiting (Simmons, Grayden \& Mitchell, 1986), dehydration due to excess purging, and potentially binge-induced gastrointestinal problems such as salivary gland hypotrophy (Mitchell, 1995). Both anorexia and bulimia nervosa are also associated with psychiatric comorbidities such as depression (Swift, Andrew, \& Barklage, 1986), anxiety (Laessle, Kittl, Fitcher, Wittchen, \& Pirke, 1987), and personality disorders (Vitousek \& Manke, 1994).

Many of the struggles associated with eating disorders have also been depicted in the popular press. A wide variety of biographical and autobiographical mainstream books have provided moving, accessible descriptions of quite harrowing experiences (e.g., Krasnow, 1996; Lee, 2004). Similar, condensed accounts can be found in magazines and newspapers (e.g., Smith, 2004). Unquestionably, eating disorders are sources of great intrigue and fascination to the general population and this is reflected in the associated increase in levels of media coverage 
(Gorrell, 2001). They currently represent psychopathological conditions with large public profiles.

With an illness of this growing magnitude it is important that the world of research continues to accept the responsibility of improving understanding through diverse and effective study. Progress on this challenge has undoubtedly been made. A variety of edited reference books (e.g., Brownell \& Fairburn, 1995; Piran, Levine, Steiner-Adair, 1999; Szmukler, Dare, \& Treasure, 1995) and specific scientific journals established in the area illustrate the broad lines of research undertaken by a variety of specialists, all of which have contributed to the current knowledge base. Regardless, the unknown far surpasses that which is known. Russell's (1970) suggestion that no clear-cut causes for eating disorders have emerged retains its salience in the current climate, and therefore, further research remains a priority.

One emerging trend of study concerns the role of participation in sport as a possible precipitant to eating disorder development. The fundamental, frequently cited, postulate is that pressures to be thin for performance gains may trigger eating disorders in vulnerable athletes (Garner, Garfinkel, Schwartz, \& Thompson, 1980). This proposal holds strong face validity as exemplified through the disturbing cases of a number of elite athletes. For example, world-class gymnast, Christy Henrich, died at age 22, weighing only 61 pounds (Noden, 1994). Over ten years earlier, elite distance runner, Mary Wazeter, threw herself from a bridge in an attempt to escape her destructive obsessions with food (Wazeter \& Lewis, 1989). Her suicide attempt, not the first or last, left her confined to a wheelchair for the rest of her life. These accounts suggest that eating disorders in athletes can be as damaging and life endangering as they are to individuals in the wider population. Henrich and Wazeter seemed consumed by a relentless pursuit for success in their respective sports, both of which placed great value on being lean for performance. The trauma that was experienced by both individuals in itself provides a rationale for the study of eating disorders in sport. Their accounts, although richly illustrative of the influences of elite sport on eating psychopathology, are void of significant psychological insight and largely ungrounded by relevant theory. The broad aim of this study was to take the personal story of an athlete, who experienced an eating disorder, and place it in the context of relevant literature. In taking a life history approach, rare in the extant eating disorder research, we hoped that the rich description and evocative narratives found in the popular press would be 
supplemented with interpretations informed by relevant scientific knowledge.

Although the understanding of clinical precipitants to eating disorders in females in general is by no means complete, the aetiology for eating disorders in males is substantially less so. This has occurred despite Striegal-Moore et al. (1986) having stated that males represent an important group to study. Such an opinion appears validated in a recent study by Braun, Sunday, Huang, and Halmi (1999) that found the number of males admitted into an eating disorder unit in the United States increased significantly between the years of 1984 and 1997. The stigma associated with what is often perceived as a "female disease" is likely to prevent many other males from seeking professional help (Carlat \& Camargo, 1991). This finding is particularly indicative of the sizable nature of the problem.

It is apparent that despite increasing societal pressures to conform to an unrealistic bodily ideal and rising prevalence estimates, males with eating disorders remain a largely neglected group. The world of sport represents an environment where male body and weight preoccupations may be accentuated yet male athletes are similarly neglected. The attraction of female athletes to suggested high risk "lean” and appearance-based sports, in combination with the well-documented female vulnerability, has not resulted in many investigations involving either males or sports termed normal-build. We, therefore, proposed that the study of a male with a history of both bulimia and participation in football at the elite level would help break the gender and lean-build research bias, and provide new insights into the relationship between eating disorders and sport. We adopted a life history methodology in an attempt to move away from the prescriptive correlating of variables that do not adequately reflect athletes' own experiences. Instead, the life history method enables the relationships between the person, the sport, and the eating disorder to be viewed in a longitudinal, developmental fashion. The comprehensive accounts typical of life history study will enable the intricacies and idiosyncrasies of such a unique case to be revealed and add to the knowledge base of the current literature.

\section{Method}

\section{The Participant}

Mike (a pseudonym) is a full-time coach at a professional football club in the United Kingdom. Previous employment as a physical education teacher and sports development officer 
are reflective of an identity shaped around sport. In his mid-20s, Mike is a fit, healthy, and confident individual. His attraction to, and success in, community roles illustrate his aptitude for working with others: "I’ve always been a people person....always a desire to be involved with people.” Appreciated by family, friends, and colleagues, he is well-liked and well-loved. Today, Mike is happy. His current state of career success and emotional contentment was preceded by a long period of psychological difficulty. At 17, Mike developed an eating disorder. Although constantly striving for the perfect physique and athletic excellence, he was unable to maintain his strict, ideal diet. Having eaten something he believed he should not have - "a momentary lapse” - he decided to make himself sick. The guilt experienced at cheating his relentless pursuit of athletic perfection was washed away and replaced by a sense of relief. Mike had discovered bulimia. As the illness escalated, severely disordered eating became physically and emotionally destructive, and years of confusion and despair were endured: "Life became a real uphill struggle to the point when it crossed my mind that I've got this forever and it's going to get the better of me and this might be, ultimately, what is the end of me.” It was difficult to understand. Mike came from a strong, loving, family and recalls an enjoyable childhood. There were no traumas, and no devastating setbacks: “I had everything going for me....people wouldn’t mind being me.” Now recovered, the methods employed in this study depict Mike’s story, the understandings he has managed to form, and the meanings he gives to explaining his life as lived.

\section{Life History Method}

The life history is a method of research emphasizing the inner experience of individuals and its connections with changing events and phases throughout the life course (Cole \& Knowles, 2001a). It involves a written reconstructed narrative account, elicited through interviews, by researchers who seek to understand the life of another (Tierney, 2000). The roots of the method are planted in constructivist philosophies, and its epistemological assumptions are interpretivist. The recent resurgence of the life history as a legitimate research method has coincided with a current focus on acknowledging the subjective and multiple nature of human experience (Sparkes, Schempp, \& Templin, 1993).

The life history's portrayal of whole lives and ongoing development is particularly useful for the study of eating disorders in sport for which longitudinal depictions are lacking (Petrie, 1996; 
Smolak, Murnen, \& Ruble, 2000). The use of life history work in the understanding of psychological phenomena is not new (Erikson, 1958, 1969). Ricks, Thomas, and Roff (1974) suggested that life histories and personal biographies are essential for the understanding of mental disorders. Specifically, Ricks (1974) stated that knowing how a disorder begins, evolves, and is maintained can provide the best clues as to how to change the pattern. Life histories may also be particularly useful when attempting to gain knowledge regarding relatively unconsidered psychopathology. For example, Ricks, in discussing the life history stated "longitudinal research is necessary if we are to get an adequate conceptual handle on new problems, for which there is no accumulated clinical experience and not enough time in which to accumulate it” (p. 351). The issue of males with eating disorders meets this criteria.

\section{Interviews}

Data were gathered through a series of semi-structured interviews that I (first author) conducted by inviting Mike to look back over his entire life course (Cole \& Knowles, 2001a). Interviews flexible in structure are typical in qualitative inquiry providing depth and breadth of insight. Fontana and Frey (1998) view this flexibility as an attempt to understand the complex behavior of members of society without imposing any a priory categorization that may limit the field of inquiry. This definition emphasizes the inductive properties of the qualitative interview. If categories are not imposed, previously unconsidered phenomena can be revealed. This is of relevance in context of the exploratory nature of the topic in question. Specifically, when exploring new ground one should adopt a flexible interview approach (Fielding, 1993).

Prior to engaging in interviews Mike signed an informed consent form. A series of nine interviews were conducted over a 4-week period and ranged from 60-105 minutes in length. On completion 11 hours of life history data had been gathered. The broad focus of the research, Mike's athletic career and eating disorder experiences, shaped the telling of the story. The first interview involved a more guided approach than the subsequent ones, focussing the discussion towards Mike’s childhood experiences and family life. From early childhood memories interviews progressed to the present day. Mike’s narrative moved logically through school, college, university, and employment periods. In acknowledging and seeking subjective reality Mike led the interviews and was encouraged to digress. Points deemed interesting and worthy of exploration were then probed. With Mike’s consent all interviews were tape recorded and 
transcribed, and this enabled important interviewer roles such as active listening, observing verbal and non-verbal cues, interpreting, and prompting to be focussed on without the distraction of taking field notes during the interviews (Mason, 2002). After each session the interview tape was listened to in full. This early submersion in the data permitted preliminary analytical and interpretive speculations to be made and to produce a written summary. This process also enabled the identification of issues warranting clarification or further investigation which then contributed to the interview guide for the subsequent session. I had a final member check interview was conducted with Mike once analytical interpretations had been made.

\section{Friendship as Method}

It is important to acknowledge that the relationship between Mike and me is one of friends. The friendship was originally formed while representing the same university football team and centered largely on organized social events for the team. Later, serendipitously, we would take up full-time employment positions at the same college of further education and live in the same, shared accommodation for a period of three years. It was during this period that our bond as friends strengthened further.

Research as a friend into the life of a friend influences the roles of gathering, analyzing, and interpreting. It is, therefore, important to be reflexive regarding these issues. With regards to friendship, a number of authors have begun to recognize the value of studying individuals with whom there is a close, existing relationship (Austin, 1996; Bochner \& Ellis, 1992; TillmanHealey, 2001, 2003). For example, Tillman-Healey (2001) used her own friendship with a group of gay men to provide insights into understanding friendships across sexual orientation. Further, many of the principles instrumental in effective qualitative inquiry are synonymous with those of friendship. Specifically, in friends we seek trust, honesty, respect, commitment, mutuality, understanding, and acceptance (Rubin, 1985) and these correspond closely to the values of relationality, mutuality, and empathy, identified as guiding life history research (Cole \& Kowles, 2001a). Further, Cole and Kowles (2001a) have stated that the more blurred the boundaries between the personal and the professional, the closer one gets to knowledge producing. Similarly, Oakley (1981) suggested authentic knowledge will only emerge from authentic relationships. Clearly, there are great research benefits gained from the existing intimacy and authenticity present in the my friendship with Mike. As illustrated in the following 
extracts from the interview transcript, the existing trust enabled a more open research process and the disclosure of valuable personal information:

"I think this is the first time where I'm not scared...of what's going to be done with the information because I know who you are and I know you're not going to twist stuff....I feel completely comfortable telling you all this stuff and as I've said I've told you things I wouldn’t tell other people” .

The method of interactive interviewing (Ellis, Kiesinger, \& Tillman-Healey, 1997) is cited as being closest to achieving friendship as method. Interactive interviewing emphasizes the collaborative nature of interviews whereby both researcher and participant engage in intimate and joint sense-making regarding emotionally charged, sensitive topics (Ellis et al., 1997). Although not central to the interviews, I drew upon principles of interactive interviewing at critical moments. For example, my own role in the life history of Mike enabled him to assist in the recollection of key events that we had both experienced. The following extracts exemplify one such joint endeavor at story construction:

Mike: “I’d been fine until about September/October...had binged again a little bit, then started seeing someone (clinical psychologist) around that time”.

Interviewer: "I thought you were seeing someone earlier than that around the time we..."

Mike: "I may well have had an initial assessment I think...thinking about that you're right, yeah, good memory.”

\section{Analysis and Interpretation}

Bertaux (1981) has argued that the narrative collected from life history research can stand alone as an important source of knowledge. In contrast, Goodson (1988) claimed that in not placing subjective experience within a broader contextual analysis the researcher is taking "a profoundly conservative approach” (p. 240). Similarly, both Denzin (1989) and Hatch and Wisniewski, (1995) stated that it is the analysis and interpretation of the contexts of a life that move it from life story to life history.

Effective life history analysis has been associated with the highlighting of critical incidents, fateful moments, or epiphanies (Denzin, 1989; Giddens, 1991). Denzin’s notion of epiphanies as “interactional moments and experiences which leave marks on people’s lives” (p. 70) is an effective starting point for analysing biographical data. Life's turning points as events or non- 
events, as leading to changes in identity, character and subsequent behavior, as potentially productive or destructive, are characteristics of both Schlossberg's (1981) transitions and Denzin’s epiphanies. Epiphanies, in essence, represent life transitions and hold a number of similarities to the work of Schlossberg. As part of the data analysis, transitions were identified from the gathered life narrative to serve as the fundamental organizing points around which the life was retold (Cole \& Knowles, 2001b). This process involved repeated reading of the interview transcripts to gain a complete appreciation of Mike’s life, increasing the authors' sensitivity to major events or non-events that caused change. Only the transitions considered most pertinent to Mike’s eating disorder experience were selected for analysis. Once identified, Mike verified (or not) their relevance.

Given Schlossberg's (1981) parallels with the interpretive biographical work of Denzin (1989), her model of human adaptation to transition was used to evaluate identified transitions. This model encompasses three key constructs: the transition characteristics, including role change, affect, source, timing, duration and degree of stress; the characteristics of pre and post transition supports and physical settings; and the individual's characteristics, including, sex and sex-role identification, age and life stage, health, race, socio-economic status, value orientation and previous experience with similar transitions. The salience of these factors to adaptation varies according to each transition. The model is a tool employed to illuminate the life history not vice-versa. The authors considered Schlossberg's constructs diverse enough to provide a discursive framework for the principal features of a developing life without the need to prescriptively guide interviews towards their individual facets. This process enabled the model to be used without sacrificing the qualitative ideology of subjective, personally constructed reality.

Through listening and re-listening to tape recordings and numerous re-readings of transcripts, I became enmeshed in the data and created a representation of the critical elements of life before, during, and after Mike’s identified transitions. With features of one transition expectedly influencing subsequent transitions, the ebbs and flows of the life as lived were depicted. This fluidity accessed the connectedness and interrelatedness of human life in a way not possible through the popular, yet rigid, categorization employed in content analysis (Cole \& Knowles, 2001b). 
Interpretations of life transitions were not based on any single set of prescribed postulates, and hence, did not restrict or confine the data. Such an approach would conflict with the fundamental principles of accessing subjective experience and enabling the portrayal of personal realities. Rather, interpretations should be enriched by diverse theories that may even cross disciplines (Sparkes et al., 1993). Specifically, after emergent themes had been identified, we reviewed the relevant literature and made analytical links. We deemed this process essential for investigating the full complexities of life for which there is unlikely to be an all-encompassing explanatory theory. Further, we also discussed life experiences within the context of existing literature surrounding eating disorders in general and in sport. This enabled a comparison between Mike's actual lived experience with an eating disorder and the processes described in the largely positivist literature.

\section{Member Checking}

Member checking (Lincoln \& Guba, 1985) was employed in this study by initially forwarding all transcripts to Mike on completion. I then invited Mike to give his retrospective opinions on the accuracy of my statements made as well as offer further information where he felt detail was lacking or important issues not addressed. Further, during the analysis process I regularly contacted Mike to confirm the exact meaning of various statements and opinions made during interview. Both these steps facilitate the collaboration and dual meaning-making process necessary to ensure emerging data are the respondent’s (Manning, 1997). Finally, I asked Mike to comment on the interpretations and conclusions I offered regarding his life history. This is not to say any rebuttal of suggested interpretations would have rendered those interpretations invalid. Such an assumption conflicts strongly with constructivist notions of multiple realities where both the authors as researchers and Mike as the researched possess our own, unique, subjective, yet equally legitimate realities (Fielding \& Fielding, 1986). My views of Mike were, therefore, sought not for verification purposes but rather as an alternative source of insight (Fielding \& Fielding, 1986). Consequently, Mike’s views on offered interpretations were recorded and transcribed.

\section{Results and Discussion}

Mike's life history is presented together with the various interpretations offered and associated discussion points. It is proposed that in integrating transcript extracts with the 
associated theoretical insights a more coherent analysis is achieved. The structure is provided through the key life transitions identified from the transcripts in order from the earliest to the present day. Each transition is explained, its pre- and post-transition environments described, and how each ultimately influences Mike, interpreted.

\section{The Early Years}

The memories Mike holds of his life as a child are fond ones. The story he tells is of a joyous time, shared with a loving family:

"We used to do a lot as a family when I was a kid. Particularly holidays... we had cousins who lived on the Isle of Wight. They live in a massive house, no one around, lots of space and the kids would just go off and play, play sport and have adventures non-stop for what seemed like weeks on end over the summer holidays...almost idyllic.”

His relationship with his parents, a primary school teacher mother and a social worker father, was characterized by its normality. The younger of two boys, Mike admired his brother who is three years older: “As kids, I looked up to him, he was my hero.” This familial stability and absence of trauma is symptomatic of Mike's life throughout childhood and adolescence. Although conflicting with some theorists who have suggested traumatic life events precipitate eating disorders (Schmidt, Tiller, Andrews, Blanchard, \& Treasure, 1997), it serves as a backdrop to Mike’s experience.

\section{Secondary School}

The move from primary to secondary school is identified as the first important development in the life-course. This normative transition is characterized by increased choices and changes in an adolescent's world (Newman, Lohman, Newman, Myres, \& Smith, 2000).

Pre-transition environment. During his primary school years Mike pledged no specific allegiance to any one activity. He engaged in a range of activities including piano and drama club, the latter in which he particularly excelled. In terms of sport, although possessing definite aptitude, participation was equally varied and often informal and unstructured. Such exploration of differing roles is critical to the opening up of a foreclosed identity (Marcia, 1966). This was facilitated by his parents who granted autonomy with regards to hobbies. The diversity suited Mike: "I was a doer...spent all my time out, with friends, doing stuff."

Post-transition environment. The move to secondary school and the promotion of more 
formal, structured sporting activities saw a reduction in the range of activities Mike engaged in. Specifically, activities were demanding more time and Mike was required to make choices.

Discussing drama and swimming, both significant elements of his childhood, Mike states: “...I would have given it (drama) up once I'd gone to secondary school, because it clashed with the club football training on a Thursday night" and "I got given the opportunity to become a ridiculous swimmer getting up every morning...given the choice between football and swimming, I took football on board more.” These choices are critical in terms of identity development. Erikson (1968) suggested identity formation occurs when an adolescent selects some identities and discards others in accordance with their interests, talents, and values. In essence, Mike engaged in this process and opted for an identity that centered on sport, and specifically football. Although some activity diversity remained, it is unlikely sufficient exploration of other identities had occurred by this age resulting in identity foreclosure (Marcia, 1966). This is common in young athletes due to the all-consuming dedication required for success in sport (Taylor \& Ogilvie, 2001). As a result, identities formed around sport are often narrow. Mike’s self-identity during secondary school, from his own perspective, support this: “at school, I was captain of all the teams, I did everything, even the stuff I didn’t particularly enjoy I got roped into because I was good at it.”

Being roped into activities suggests Mike’s sporting capabilities were earning him recognition and praise, and this may have accentuated the exclusivity of the identity formed. Research has shown that the satisfaction, glory, and prestige (Alder \& Alder, 1989) associated with an athletic identity render other identities less attractive. This is further exemplified in the following statement: “I could get on with the sort of macho hard lads even though I wasn’t particularly cool because I was good at football.” In being continuously responded to in terms of a specialized sports role, Coakley (1992) suggested a narrow, socially-constructed identity is formed. Such reinforcement of athletic endeavors may have led to not developing alternative skills, and hence, diminish possible alternative identities. Mike’s skills as a student would be affected in this manner: “although I was ‘sporty’ I thought I was thick...I wasn’t thick...people would make fun of me and call me thick.” With academic competence not acknowledged and even ridiculed, a reduction in self-esteem in this domain was inevitable.

\section{Elite Football}


At the age of sixteen Mike joined a high profile local football club. Competing against a number of professional club youth sides the move represented a marked leap in playing standard.

Pre-transition environment. Mike’s football experiences with his school team and local junior side were always personally successful. Regardless of the result, Mike, as captain, would invariably be the best player on the pitch. Indeed, while his junior team often suffered large, humiliating defeats, it was possible to gain solace from his own outstanding performances that far surpassed those of team-mates. Naturally, this success was revelled in by Mike and his family alike who would talk about his games for hours at a time. Football was enjoyable and it was easy. Mike had begun to harbor dreams of becoming a professional football player.

Post-transition environment. On joining his new club Mike noticed an immediate change: "I wasn't the best in the team, for the first time ever.” Though adapting to this initially, in his second year at the club it had become harder to maintain the required standard. Whilst still enjoyable football ceased to be easy: "all of a sudden I was getting nervous before games which had never happened before.”

Mike had perceived a serious threat to his previous football achievements. Interestingly, Coakley (1992) suggests failure threats are more pertinent when an athlete has a singular identity as they do not possess alternative identities on which to fall back on. Football had thus become so important to Mike, so intertwined with his identity, that dangers to current success were particularly threatening as they corresponded to threats to self and possible identity loss. With threats to achievement linked with eating disorder development (Levine \& Smolak, 1992), his eating disorder risk may therefore have been accentuated. Indeed, this may explain the currently equivocal findings regarding the relationship between elite sport and eating disorder risk (Fulkerson, Keel, Leon, \& Dorr, 1999; Hamilton, Brooke-Gunn, Warren, \& Hamilton, 1988). Specifically, an exclusive athletic identity may act as a moderating variable to disordered eating, its presence heightening fear of failure and thus heightening risk. An elite athlete with a more diverse self-identity will hence be less susceptible. Future research should address this appealing hypothesis.

Mike became quickly aware of other changes: "the emphasis now on training was on being fit, as a kid the emphasis had never been on being fit" and "No one had ever mentioned food or 
diet...but people were all of a sudden.” This emphasis on diet and leanness for performance is unusual in a sport typically classed as non-lean where it is thought such pressures are to be minimal (Bryne \& McLean, 2002; Davison, Earnest, \& Birch, 2002; Hulley \& Hill, 2001). This represents a critical finding as it may be proposed that the general emphasis on fitness and diet characteristic of all sports, not purely those of an aesthetic nature, can be sufficient to precipitate disordered eating in vulnerable individuals. Mike was one such individual and determined to counter perceived achievement threats these environmental cues regarding food, diet, and fitness were seized and put into practice: “I had the perfect diet, wouldn’t eat McDonalds, you know, wouldn’t eat chocolate... what I perceived to be the perfect diet for a sportsman.”

With eating disorder onset regularly shown to be preceded by such periods of intense dieting (Heatherton \& Polivy, 1992; Wilson, 1993), Mike was engaging in dangerous practice. Also underpinning his controlled eating were perfectionist tendencies: "I think I do things to perfection...that's my make up, I've got this desire to strive for perfection.” Put simply, Mike had applied his perfectionist tendencies to the fitness and diet cues he had detected in his sport setting by establishing strict dietary control. This is an important insight into the complex process that underlies previously identified empirical associations between perfectionist athletes and more restrained eating (Fulkerson et al., 1999).

Mike also began to equate a lean physique with fitness for performance. This inaccurate belief, often linked to disordered eating (Sherman \& Thompson, 2001), further spurred Mike’s adherence to a tightly controlled diet: “well he’s probably the best in this team, look at his physique, look how fit he is.” Mike’s normative comparisons continued in other life domains. This resulted in a more general body image dissatisfaction and a greater urge to achieve the male ideal. Mike's definition of this was consistent with the muscular, mesomorphic ideal described in the literature (Furnham \& Greaves, 1994; Grogan, 1999). His perfectionist tendencies however ensured he would never reach this goal hence the diet continued amidst obsessive weighing, mirror checking, calorie counting, and exercise. This conflicts with researchers' assumptions that men's quest to be larger rather than thinner reduces concerns with weight and hence eating-disorder risk (Page \& Allen, 1995; Raudenbush \& Zellner, 1997). Drawing on Mike's experience such a suggestion is naïve as to the nature of the extra size sought which is likely to be muscle-based. Specifically, the pursuit for a larger, yet lean and 
muscularly defined physique, requires as stringent dietary control as one based purely on weight reduction. Similarly, the suggestion that muscular growth in puberty brings adolescent males closer to their body ideal (Striegal-Moore, 1993) seem insensitive to the extreme facets of such a look (Leit, Pope, \& Gray, 2001) and the effort required to achieve it.

The emergent features in this transition are largely in tune with much of the reviewed literature regarding sport and eating disorder risk. This similarity is a critical finding in itself as it has occurred in a male and within a football environment. While aesthetic sports are undoubtedly more overtly weight oriented this does not account for individual perceptions: "I think there [football environment] it was pure pressure I was putting on myself.” Hence, while the emphasis on weight may not have been excessive, in Mike's reality it was parallel with that experienced at times by gymnasts and figure skaters (Ryan, 1996).

\section{A-Levels}

Overlapping with Mike’s change of football team was an additional transition featuring a move to a school to study A-Levels. In the United Kingdom, an A-Level (short for Advanced Level) is an educational qualification taken by students (normally aged 16) over two-years as a pre-requisite for university admission.

Pre-transition environment. Mike’s capabilities as a student were disparaged as early as primary school: “I remember teachers telling my parents, lovely kid, but he ain’t going anywhere, not bright enough.” Mike’s own views regarding his performance through secondary school are similarly uninspiring: "I was just average, middly-diddly...I just sailed along.” As previously averred, perceptions of himself as unintelligent, in his view a function of his sporting success, were shared by teachers and peers, becoming the focus of the latter's mocking. Given Mike’s subsequent, substantial academic and vocational achievements it is feasible to assume this mediocrity may have been the result of a self-fulfilling prophecy. That is, the behavior of Mike’s peers and teachers, as influenced by their expectations of him as non-academic, caused Mike to fulfil those very expectations (Rosenthal \& Jacobson, 1992). This may have been facilitated by a heightened eagerness to please others: "I kind of took on this persona of being an idiot and probably played up to it because it was entertaining.”

With an assumed lack of intelligence perceived as amusing, Mike willingly accentuated the character to gain social acceptance. This illustrates a characteristic of Mike's personality he 
readily acknowledges: "I wanted people to laugh at me, I wanted to be liked.” Although often offered as a predominantly female feature, this need for social approval and acceptance is concurrent with Striegal-Moore's (1993) concept of the relational self which may act as a risk factor to eating disorder development. The general importance of achieving a group identity (Newman \& Newman, 2001) and the concern with one’s appearance "in the eyes of others" (Erikson, 1963; p. 235) typical of adolescence may have further contributed to these social acceptance concerns.

Post-transition environment. To study A-Levels Mike was required to attend a school at the age of 16 that catered for his subject choices. This fresh start enabled Mike to discard many of the negative labels acquired during secondary school, increasing his confidence in an educational setting: “...for the first time I ended up in a class of people where I was probably deemed to be a little bit brighter than the rest and I think I felt good about that.” Mike's attitude had changed towards his academic studies moving from apathy to enthusiasm. Related to this was a gained appreciation, influenced by visits to his brother at university, of what the student life may have to offer. Mike therefore had a new goal to accompany his sporting pursuits and with it came similar pressures. After poor performance in his first year, Mike realized that to achieve the grades necessary to attend his course of choice, his results would need to improve dramatically. This represents an additional achievement threat that would run parallel with his football concerns, thus further increasing eating disorder vulnerability (Levine \& Smolak, 1992). Mike responded similarly, with the perfectionism applied to his diet also applied to his studies: "I kind of got into robot mode kind of that regimented thing again...really regimented kind of structure, so a pile of stuff that needs to be learnt and a pile of stuff that is already learnt...I just worked ridiculously hard.” That both the football and school transitions occurred concurrently is important. The culmination of the described social and psychological pressures of the two situations interacted with Mike's perfectionist and relational personality to instigate his first purging episode. Mike was soon meeting the DSM-IV criteria for bulimia nervosa (American Psychiatric Association, 1994). Consistent with the literature regarding typical age of onset, he was seventeen years old (Olivardia, Pope, Mangweth, \& Hudson, 1995; Carlat, Camargo, \& Herzog, 1997).

University 
Leaving home for university has been considered a transition into adulthood, and the adjustment required has been shown to be both stressful and negative (Pancer, Hunsberger, Pratt, \& Alisat, 2000).

Pre-transition environment. Prior to his move to university Mike engaged in daily bingepurge cycles. The stress lifted through the ending of the football season and the completion of university preparatory exams did not alleviate symptoms: "long days when nothing really happened...I think probably just the opportunity to eat was there in the house on your own.” His behavioral irregularities were somehow detected and Mike was approached by his concerned father. Fervently denying suggestions of disordered eating his word was accepted. The incident however was shocking and frightening, serving to underline the very real existence of his illness and its full severity. Interestingly, the struggles experienced would positively influence Mike’s attitude towards the forthcoming move: "this is a new start and maybe this is the time that I eventually shake off this illness.”

Post-transition environment. Initial adaptation, in normative terms, was successful in many ways. Mike made a number of new friends, settled well into his new surroundings and began enjoying student life. With specific reference to the eating disorder, the transition made an immediate and direct impact. Primarily, while bingeing continued, Mike completely ceased selfinduced vomiting as a method of purging for fear of being heard in his new, compact, living arrangements. Indeed, purging of any kind was stopped. This new, atypical manifestation (Fairburn \& Walsh, 1995), whilst never officially diagnosed, closely resembled the DSM-IV description of binge eating disorder.

Studies addressing eating disorders in university samples have, in the main, addressed issues of prevalence (Heatherton, Nichols, Mahamedi, \& Keel, 1995) and general eating attitude change (Vohs, Heatherton, \& Herrin, 2001). Few have investigated how a move to such an environment influences individuals with an existing eating disorder. Mike found his condition exacerbated: "I was the one doing the weekly shop. I was cooking, I was preparing, and no one told me when I had to eat. And that's when the eating habits just kind of dissolved completely.” This autonomy granted by the transition, proved, in this instance, destructive.

A further change of particular relevance concerns Mike’s altered involvement in football: “It wasn’t a win at all costs. It was university have a laugh, have a few beers...I was back 
To being one of the better players...the whole fitness thing went out the window 'cos university life everyone was drinking beer, everyone knew they were there for a degree and not to become professional footballers...for the first time now I had an eating disorder and not the football”.

This is a crucial finding given the view that many instances of disordered eating in sport are purely behavioral as opposed to psychopathological, ceasing when sport is withdrawn (Dale \& Landers, 1999; King, 1989; Ziegler et al., 1998). While not invalidating such a perspective, it does illustrate that sporting pressures may, in certain individuals, help induce a clinical psychosis that remains when such pressures are eased.

\section{Final Year at University}

The progression to the final year of university is characterized by increased pressure. In the United Kingdom, a greater percentage of marks is awarded in the final year and the completion of a thesis is necessary to achieve honors degree status.

Pre-transition environment. For the first two years of university Mike learned to live with his disorder: "it wasn’t depressing me, it wasn’t getting me down, it was almost like I'd grown to get used to it...it really wasn't particularly affecting daily life”. Related to this was a genuine optimism that recovery would occur: "every day I woke up in the first year I was thinking today is the day that it's not going to happen again”. Mike had also informed a close friend of his disorder, providing an invaluable source of social support. The presence of a supportive relationship is said to assist effective coping with stressors (Hobfoll \& Stephens, 1990; Paykel \& Cooper, 1992). Mike was less interested to tell other people, however, experiencing considerable embarrassment regarding his illness: "With an eating disorder, particularly as a guy, in my head I thought that people's reaction would be what a freak, what a weirdo so it's something that you desperately wanted to keep secret.” This statement accurately captures the fear of stigmatization that research suggests plagues male sufferers of eating disorders (Carlat \& Camargo, 1991; Carlat et al. 1997). These feelings were worsened by the rarity of such conditions within football, which while played less competitively remained a strong part of Mike’s identity: “models have eating disorders, Mike and sportsmen don’t. Certainly not footballers. Gymnasts, ballerinas, but not footballers.” Consequently, the illness and its various symptoms remained hidden. Mike portrayed an alternative side of his character, the happy, 
confident, healthy side that would conceal any underlying morbidity. Mike’s self-presentation may also have functioned as a form of coping, serving to minimize the pertinence of his inner struggles (Goffman, 1990).

Post-transition environment. On entering the final year of university Mike's eating disorder worsened dramatically: "I would be bingeing every day possibly all day, ridiculous amounts of food, doing anything to get hold of food”. The associated disturbance of affect was considerable: "I did go into this depression and I was sleeping in the day, I wouldn't speak to people”. Reflecting on this time he cites a number of explanations: "I suppose the lifestyle just became a bit more hectic, more pressurized, so the final year of university...the reality of the fact that this was kind of a crunch time.” Life's stressors have been identified as possibly precipitating binge episodes in binge eating individuals as they act as a coping resource (Hawkins \& Clement, 1984). This reprieve is temporary, however, giving way to associated feelings of guilt and depression (Elmore \& De Castro, 1990). In sum, the more stressors Mike experienced, the more he binged and consequently the more depressed he became.

This deterioration thwarted Mike’s optimism regarding eventual recovery and induced feelings of resignation: “it got to the point where I woke up feeling today isn't the day [the bingeing would stop], today is like any other day so I may as well start bingeing now at nine o'clock in the morning rather than trying to fight it until 6 o'clock today. I kind of resigned to it”. These comments suggest Mike was experiencing learned helplessness, the belief that all action is futile (Seligman, 1992), which may have been an additional source of depression. Specifically, Seligman suggests the depressed patient believes he cannot control the elements of life that may relieve suffering. For Mike, therefore, depression may have partly been the result of his perceived inability to cease bingeing.

The continued deceit involved in keeping the disorder hidden would also take its toll around this critical time: "there was a kind of turmoil within myself that what people thought they were seeing was not really what they were seeing”. Mike’s incomplete self-presentation no longer assisted coping, but rather caused further psychological disturbance. Jourard's (1971) views on the benefits of the transparent self may provide some understanding of this change. Jourard suggests that complete and honest self-disclosure, a transparent self, is necessary for physical and psychological health while concealment can cause guilt and self-alienation. In addition, 
Jourard has stated that "in the effort to avoid becoming known, a person provides for himself a cancerous kind of stress” (p. 33).

Also offered as a contributing factor to Mike's deteriorated situation was the move abroad of the friend who he had informed of his eating disorder: "She was a person who knew and had been there to support me who wasn't there any more”. A lack of social support has been associated with both negative coping with stress (Paykal \& Cooper, 1992) and depression (Feldman \& Gotlib, 1993). Mike’s increased bingeing and depressed state support this.

\section{Treatment}

At twenty-two years of age, after a six month waiting list, Mike had his first session with a clinical psychologist. The effects of treatment were rapid and considerable.

Pre-transition environment. The described depression that characterized Mike's final year at university also forms the crux of the current pre-transition environment. Mike’s lack of coping resources, with regards to his illness and associated depression, led to recurring destructive behaviors: "I used to go out on the beers and not sleep and go straight to lectures. I must have been a disgrace”. Similarly, he voluntarily organized a major social event for the University Athletics Union as well as smaller gatherings for his university football team. He reasons: "I launched myself into the stuff that was enjoyable wholeheartedly while the rest of things fell apart”. Such escapist actions are symptomatic of avoidance-based coping strategies which involve avoiding a stressor without actually addressing it (Zeidner \& Saklofske, 1996). It is suggested that such strategies, while possibly providing short-term relief, are essentially maladaptive and may even increase stress over time (Lazarus \& Folkman, 1984).

Critically, the desperation that characterized Mike’s depressive existence would ultimately force him into more positive action: "I got to this point where I then could tell myself, no, I have to do something because I can't cope. I don't want to have to deal with this anymore. Had to get to rock bottom I think”. He began researching his disorder and obtained a number of readings. Such a process, referred to as searching for information (Carver, Scheier, \& Weintraub, 1989), has been identified as an effective coping strategy. Eventually, in what was a hugely traumatic experience, he visited his doctor and was put on a nine month waiting list. Having deferred his university thesis to the following year, the waiting period occurred in the same university environment and involved continued alcohol-fuelled escapism. 
Post-transition environment. On entering into treatment Mike was introduced to a number of cognitive-behavioral strategies:

“it was really dealing with...the habitual side of it 'cos that's what had gone....almost

without thinking about it I would binge and it was a case of bringing back this control and this habitual...because I'd forgotten how to do it."

Mike's habits correspond to his eating behaviors, and these were progressively altered with a list of rules prompting more structured eating patterns. Behavioral techniques of this kind have been identified as the first stage in treatment for bulimia nervosa and binge eating (Fairburn, Marcus, \& Wilson, 1993). Secondly, an individual's thoughts, beliefs and values, considered key to eating disorder maintenance, are challenged through cognitive-restructuring processes (Fairburn et al., 1993). Mike provides a specific example of this: "it was highlighted to me that I had to eat something like...over a thousand calories, probably more than that, of your normal daily intake, to even put on a pound...it was trying to challenge my thoughts.” The final stage concerns maintaining the new attitudes and behaviors. Specifically, relapse-prevention was employed which encourages behavior change by identifying strategies to cope with high-risk situations while also accepting relapses as learning curves necessary for recovery (Marlatt, 1985, 1995):

“The big one for me that helped the most was relapse. She said that you won’t get better without a relapse. It's going to happen. And again we then made contingencies for relapse, what do I do after I’ve binged?”

That this was perceived as most beneficial is perhaps a reflection of Mike's perfectionism. Justifying relapses as necessary may have eradicated unrealistic expectations of a perfect recovery, which, given its unlikelihood, may have been damaging (Fairburn et al., 1993).

Ultimately, these described cognitive-behavioral strategies may be viewed as the more adaptive problem-focused coping strategies (Lazarus \& Folkman, 1984) that were unavailable to Mike prior to treatment. Mike's health, mood, and eating patterns vastly improved, and he went on to successfully complete his university thesis.

\section{Recovery}

Recovery, particularly from a relapse prevention perspective, is a process that is assisted by a number of factors. Mike, however, identified a serious injury and subsequent withdrawal from 
football as a key transition that facilitated overcoming his eating disorder.

Pre-transition environment. After completing his extra year at university, Mike relocated to take up a teaching position. He did not register with a clinical psychologist in his new place of residence. Mike at this time had lapsed to a binging state that resembled his early university years: “the depression has gone, I'm a little bit more in control of things, I can go a little bit of time without bingeing, I am only bingeing at the end of the day.” With the disorder less destructive and Mike fully occupied with his teaching responsibilities, the urgency to push for recovery was lost: “it was a hassle, it was a pain I couldn’t be bothered...I had other stuff to be doing”. These other activities also included Mike’s continued football commitments. Playing once more at a good level, this proved time-consuming but far from fulfilling. Under the regime of an abusive manager Mike was not enjoying football, yet typically persevered.

Eventually, as the academic year drew to a close, time was found to seek further clinical assistance. Mike was put on a six month waiting list. The wait coincided with a period of controlled eating only for a further lapse to occur. Midway through his second year teaching the wait was over and so began further treatment. Critically, this coincided with Mike rupturing his cruciate ligaments. Once operated on, this required twelve months of rehabilitation during which no football was permitted.

Post-transition environment. Progress with the clinical psychologist was again immediate: "It was just a case of kind of refreshing and renewing all that old information.” Within weeks Mike had regained control of his eating habits. Aged 23 he had had his final binge. Insightfully, Mike comments: “I’d had enough relapses to learn.” Mike’s perceptions of the role of injury and resultant cessation of football in the recovery process are of particular significance: "this injury gave me the opportunity to do something that I would never have chosen to do, have a break from football...it definitely helped 'cos it gave me that time to myself."

Mike would never have voluntarily ended his involvement in football most likely due to fear of identity loss. It was thus only through injury that Mike was able to discover the benefits not playing would provide. Primarily these included increased free time enabling Mike to deal with life’s daily stressors which as already identified can precipitate bingeing (Hawkins \& Clement, 1984). Importantly, attention could also be directed towards implementing the cognitivebehavioral strategies provided in treatment. 
In discussing the rehabilitation program Mike comments: "it was giving me that enjoyment from exercise and football but...there was no pressure on me.” This highlights the pleasure gained from tasks that, unlike football, were not performed under pressure. Mike was hence finally withdrawn from the achievement threatening environment originally cited as precipitating his disorder (Levine \& Smolak, 1992) and possibly maintaining it. Whether sport withdrawal is necessary for recovery in other athletes is an important area for future research to address.

Mike afforded some free time to coaching, eventually earning a full-time job at a professional club. Importantly, this enabled his football-based identity to be maintained in a more enjoyable environment: "I’ve just replaced things that I've missed for stuff that I enjoy more” . This undoubtedly eased the injury transition which research suggests is particularly traumatic (Leddy, Lambert, \& Ogles, 1994).

\section{Confessions}

For eating disorder sufferers, particularly non-anorexics whose disorder is easier to conceal, the act of confessing the problem to parents is greatly feared, avoided, and, if it occurs, often distressing (Ellis et al., 1997). Parts of this transition involves issues and conflicts that are ongoing and so at times the present tense will be used.

Pre-transition environment. Mike wanted to ensure complete recovery before disclosing his experiences to significant others, particularly immediate family: "I wanted to be able to tell them I used to have an eating disorder”. During the early months of recovery Mike was concerned that any confessions might be falsified by a possible relapse. Further, Mike feared that with the presence of the disorder relatively recent, judgements regarding current mental health may have been suffered. On reaching a year without bingeing Mike became more and more confident that his last lapse had been his final one: "by getting to that year it was like that's a big enough amount of time to be able to say I used to have.”

Importantly, Mike now perceived himself recovered and was eager and ready to finally end the self concealment (Jourard, 1971) which was the cause of so much psychological distress. Further, confiding in others and gaining caring responses is important in recovering from traumatic experience (Harvey, Weber, \& Orbuch, 1990). A number of close friends were informed yielding positive, supportive, reactions. The doubts regarding prejudice and judgement 
that prompted Mike's secrecy had been unfounded. Regardless, he continued to refrain from telling his parents: "How can I tell my parents that I've been deceiving them for all this time? And that's how I felt, I felt guilty”. Crucially, with the most important people in his life still oblivious, Mike largely retained his concealed self and with it the feelings of deceit and guilt.

Post-transition environment. After numerous failed attempts Mike finally managed to tell his parents. The elicited response was calm and understanding leaving Mike happy and relieved. As the news was digested however, his parents expressed their confusion and despair. Mike returned to answer their questions but still believes there is much work to be done: “...we've never really gone into much depth. I think that will be the next stage.” Mike desperately wants his parents to achieve that depth of knowledge regarding his life though he fears this desire may not be reciprocated: “I think that they've almost made that decision between them that we know enough.”

This represents an important discrepancy that may prevent Mike achieving the transparent self (Jourard, 1971) he so craves. In not wanting to know more, Mike’s parents may be denying him the opportunity to fully disclose the information he believes is necessary to be truly known to them, hence, involuntarily, the concealment continues. Further, Mike expresses a worry that this may act as a barrier to the quality of the parent-son relationship:

“I've got this worry that they might have given up and thought it isn't the relationship we've

had...I would hate to think that either one of them dies not quite knowing what their son was all about”.

The perception that his relationship with his parents is viewed by them as some form of charade is deeply upsetting. Mike's fears are not ungrounded and a lack of truthful and full selfdisclosure has been said to make a farce out of relationships (Jourard, 1968). Specifically, it is stated "how can the other person love me if he does not know me?" (Jourard, 1968, p. 426). Resolving this issue is undoubtedly a task of critical importance and one that will perhaps shape the future of Mike's life-course.

\section{Understanding and Acceptance}

In discussing how people cope with extremely stressful experiences, Harvey et al. (1990) propose that storytelling, or the forming of accounts, is critically important. Specifically, through the forming of a complete account, one that involves understanding, acceptance, and 
identity change, recovery can occur. From here an individual may help others who have suffered similarly. There is strong evidence of these factors within Mike’s narrative.

Mike possesses a genuine appreciation that some benefits have arisen from the experience: "I think it gave me skills that I didn’t have. It taught me to appreciate what I am and who I am”. This characterizes a redemptive element to the life story whereby a negative scene is 'redeemed' by a positive outcome (McAdams \& Bowman, 2002). By depicting redemption Mike suggests a developing understanding of self as an individual growing and moving forward (Gergen \& Gergen, 1986). This facilitates the achievement of the complete account specified by Harvey et al. (1990).

Confiding the account to others has, as addressed in the previous section, been associated with recovery (Harvey et al., 1990). Mike ran a marathon for males with eating disorders but also used this event as a mechanism by which to inform everybody of his own experience. In addition, by running a marathon to raise money and awareness for males with eating disorders, the redemptive element to Mike’s narrative was developed further: "that's what led on to the whole marathon thing was the getting something good out of such a horrible situation.” As discussed, this helping of others is symptomatic of having devised a complete account (Harvey et al., 1990). This represents a form of generativity, Erikson's (1963) stage of adult development which involves concern for the next generation. Interestingly, further generative actions with regards to his eating disorder have largely been avoided. With reference to a thank you letter from a male eating disorder sufferer, who had read a marathon publicity profile on Mike, he stated: “it sounds really clichéd and people go if I can just help one person I’ve done enough, and I get the feeling that that guy probably was enough for me.” Though a generative individual, as indicated by his teaching and coaching roles, it may be speculated that for Mike, the sensitivity of the experience and need to retain closure prevents further direct generative commitments. Indirect generative actions however may still be made. A prime example is participation in this study. Specifically, a person's life narrative may be used for generative purposes in that it is told as a lesson for others to learn from (Maruna, 1997; McAdams, 1993).

Taking an Eriksonian developmental perspective, if Mike is at a stage of generativity, then final identity must now be achieved. If this is so, it can be related to the identity change necessary for recovery from traumatic experience (Harvey et al., 1990). Indeed, earlier cited 
comments regarding skills learned support this notion of change. The following quotation reemphasizes the notion of a new identity with regards to how Mike has integrated his trauma with his current conception of self: "it's a massive part of what I am and who I am, it is me. The person that sits here now is sculpted around seven years of having an eating disorder”. This acceptance of the past, how it has influenced present identity, and consequently, how it will influence the future, indicates that Mike’s recovery is, in many respects, a complete one.

\section{Study Limitations}

The limitations of this study can be divided into those relating to qualitative research in general, and those that concern the life history method. In broad terms, the findings may not be widely generalized and causality has not been identified. The study, in terms of both method (friendship) and participant (male football player with an eating disorder), would also be difficult to replicate (Cole \& Knowles, 2001a). This, however, is often required when seeking rich description and depth (Denzin \& Lincoln, 1994). Similarly, participant perceptions of causality, useful in their own right, are evident and replication of the research genre is definitely possible. Meeting such criteria is not the aim of qualitative inquiry. To counter such limitations would be at the expense of the core strengths of qualitative research and hence, one of the strengths of this study.

With regards to the life history method specifically, gaining retrospective details of a life can prove problematic. Primarily, accurate details of events, thoughts, and feelings may be difficult to recall (Stillwell \& Baumeister, 1997). This may be accentuated when recalling traumatic experience. For example, when discussing a time of great depression, Mike commented: "I lived a lot of my life in the daze then...I can't look back on stuff and remember stuff”. Recalled thoughts and feelings of the past may also be compounded by new knowledge and recent insights: “I probably know stuff now that I didn’t know then so I'm interpreting differently or...it's so hard to go back, so hard”. That this limitation has been wittingly acknowledged, it is to some degree addressed.

To accurately represent the full complexities of the life of an other is an enormous task. Achieving such a goal is limited by the focus of the study. Specifically, in aiming to depict the developmental course of an athlete's eating disorder, other emergent themes are afforded less attention. Further, representation is to some extent a function of what is revealed. As stated by 
Carey (1999), “There is much that remains hidden....What do the silences tell us?” (p. 417). While Mike's openness is apparent, it is naïve to assume nothing has been withheld, be it consciously or subconsciously.

\section{Conclusions and Future Directions}

The aim of the study was to develop a better understanding of the processes involved when athletes demonstrate unhealthy eating behaviour, and specifically, the meaning potential precipitants hold for athletes themselves in terms of subjective relevance, influence, and interaction as this may inform the inference of the causes of disordered eating in sport. Principally, Mike’s narrative suggests sport can play a part in precipitating an eating disorder in a vulnerable individual. This is in-line with the current research consensus regarding eating disorders in sport (Thompson \& Sherman, 1993).

For Mike, an emphasis on weight and diet for success and the achievement threats typical of elite sport were the environmental mechanisms by which sport facilitated eating disorder development. This is concurrent with other eating disorder in sport research (Sungdon-Borgen, 1994). However, achievement threats were also perceived as an identity threat due to the presence of a foreclosed and exclusive athletic identity. This may have increased the salience of these threats, and hence, increased eating disorder risk. Research should look to explore this interesting and encouraging avenue further.

While Mike's weight and performance concerns are comparable to eating disorder development in sports such as gymnastics (Sungdon-Borgen, 1994), previous research has neglected to highlight such a process in non-lean sports where aesthetic concerns are minimal. It may be postulated that a sport's focus on diet need not be excessive for it to be perceived as so. As weight plays some role in performance in all sports, particularly at an elite level, this is an important issue. It is, therefore, important that adequate education regarding healthy eating habits is available to coaches and athletes across all sports. This may help prevent athletes forming distorted interpretations of the dietary practice required to achieve optimal performance. Future studies should further address how athletes’ perceptions of weight pressures interact with actual emphasis on weight in increasing eating disorder risk.

Mike's pathological eating behavior remained when elite sport was withdrawn. While it is agreed that many cases of disordered eating in sport may be purely behavioral (Dale \& Landers, 
1999), it may be concluded that this is not always the case. This underlines the importance of understanding the role of sport in the onset of eating disorders, as the consequences may be chronic, remaining long after sport and its associated precipitants have gone. Further, sport psychology practitioners must be made aware that disordered eating may be of clinical severity to ensure appropriate referrals are made. Researchers should investigate other athletes whose clinical disorders remain once sport ceases in order to substantiate this finding, and we feel that further adoption of the life-history approach would be an effective means to achieving this.

The developmental course and clinical picture of Mike’s eating disorder paralleled the experiences of females. As a perfectionist, eager to please, adolescent, in a highly achievement threatening environment, Mike was at high-risk. Mike also experienced societal pressures for an ideal male physique in much the same way females are pressured towards the feminine ideal. These similarities are important in terms of current knowledge regarding males with eating disorders (Petrie \& Sherman, 2000). If the precursors to psychopathology are the same irrespective of gender, then the existing literature focus on females may be applicable to males. The plausibility of this notion should be determined through gender comparisons with regards to eating disorder development, course, and outcome, both generally and within a sport settings.

One element of Mike's life that appears gender specific was the embarrassment and shame felt in possessing what he perceived to be a typically female illness. These feelings were heightened due to Mike’s involvement in the overtly masculine culture of football. This proved a great burden throughout the full course of the condition, prompting psychologically distressing secrecy, self-concealment, and limited Mike’s social support network. It is important for researchers to assist those in sport and the wider population in breaking the "female disease" stereotype by profiling examples such as Mike. Any reduction in the stigma experienced would be a reduction of a source of considerable stress.

Interestingly, Mike’s recovery coincided with a complete withdrawal from sport participation. It is concluded that this may have taken him out of the achievement threatening environment he had endured since onset. It may also have afforded him the time to achieve a more realistic and complete identity. Future research could investigate the influence of sport withdrawal and identity achievement on athletes with eating disorders. 


\section{References}

Alder, P.A., \& Alder, P. (1989). The glorified self: The aggrandizement and the constriction of self. Social Psychology Quarterly, 52, 299-310.

American Psychiatric Association (1994). Diagnostic and statistical manual of mental disorders - fourth edition (DSM-IV). Washington DC: Author.

Austin, D. (1996). Kaleidoscope: The same and different. In C. Ellis \& A.P. Bochner (Eds.), Composing ethnography: Alternative forms of qualitative writing (pp. 206-230). Walnut Creek, CA: AltaMira Press.

Bertaux, D. (1981). The life history approach to the transformation of sociological practice. In D. Bertaux (Ed.), Biography and society (pp. 29-45). Beverly Hills, CA: Sage.

Bochner, A.P., \& Ellis, C. (1992). Personal narrative as a social approach to interpersonal communication. Communication Theory, 2, 165-172.

Braun, D.L., Sunday, S.R., Huang, A., \& Halmi, K.A. (1999). More males seek treatment for eating disorders. International Journal of Eating Disorders, 25, 415-424.

Brownell, K.D., \& Fairburn, C.G. (Eds.). (1995). Eating disorders and obesity: A comprehensive handbook. New York: Guilford.

Bryman, A. (2001). Social research methods. Oxford: University Press.

Byrne, S., \& McLean, N. (2002). Elite athletes: Effects of the pressures to be thin. Journal of Science and Medicine in Sport, 5, 80-94.

Carey, L.J. (1999). Unexpected stories: Life history and the limits of representation. Qualitative Inquiry, 5, 411-427.

Carlat, D., \& Camargo, C. (1991). Review of bulimia nervosa in males. American Journal of Psychiatry, 148, 831-843.

Carlat, D.J., Camargo, C.A., \& Herzog, D.B. (1997). Eating disorders in males: A report on 135 patients. American Journal of Psychiatry, 154, 1127-1132.

Carver, C. S., Scheier, M. F., \& Weintraub, J. K. (1989). Assessing coping strategies: A theoretically based approach. Journal of Personality and Social Psychology, 56, 267283.

Coakley, J. (1992). Burnout among adolescent athletes: A personal failure or social problem? Sociology of Sport Journal, 9, 271-285. 
Cole, A.L., \& Knowles, J.G. (2001a). Principles guiding life history researching. In A.L. Cole, \& J.G. Knowles (Eds.), Lives in context: The art of life history research (pp. 25-44). New York: AltaMira Press.

Cole, A.L., \& Knowles, J.G. (2001b). Preparing to make sense of gathered life history information. In A.L. Cole, \& J.G. Knowles (Eds.), Lives in context: The art of life history research (pp. 93-111). New York: AltaMira Press.

Crisp, A.H., Callender, J.S., Halek, C., \& Hsu, L.K.G. (1992). Long-term mortality in anorexia nervosa: A 20 year follow-up of the St. George’s and Aberdeen cohorts. British Journal of Psychiatry, 161, 104-107.

Dale, K.S., \& Landers, D.M. (1999). Weight control in wrestling: Eating disorders or disordered eating? Medicine and Science in Sport and Exercise, 31, 1382-1389.

Davis, C., Shapiro, M.C., Elliot, S., \& Dionne, M. (1993). Personality and other correlates of dietary restraint: An age by sex comparison. Personality and Individual Differences, 14, 297-305.

Davison, K.K., Earnest, M.B., \& Birch, L.L. (2002). Participation in aesthetic sports and girls’ weight concerns at ages 5 and 6 years. International Journal of Eating Disorders, 31, 312-317.

Denzin, N.K. (1989). Interpretive biography. Newbury Park, CA: Sage.

Denzin, N.K., \& Lincoln, Y.S. (1994). Introduction: Entering the field of qualitative research. In N.K. Denzin \& Y.S. Lincoln (Eds.), Handbook of qualitative research (pp. 1-17). Newbury Park, CA: Sage

Ellis, C., Kiesinger, C.E., \& Tillmann-Healey, L. (1997). Interactive interviewing: Talking about emotional experience. In R. Herz (Ed.), Reflexivity and voice (pp. 119-149). Newbury Park, CA: Sage

Elmore, D.K., \& De Castro, J.M. (1990). Self-rated moods and hunger in relation to spontaneous eating behavior in bulimics, recovered bulimics and normals. International Journal of Eating Disorders, 9, 179-190.

Erikson, E.H (1969). Gandhi's truth: On the origins of militant non-violence. New York: Norton.

Erikson, E.H. (1958). Young man Luther: A study in psychoanalysis and history. New York: 


\section{Norton.}

Erikson, E.H. (1963). Childhood and society (2nd ed.). New York: Norton.

Erikson, E.H. (1968). Identity, youth, and crisis. New York: Norton.

Fairburn, C.G., \& Walsh, B.T. (1995). Atypical eating disorders. In K.D. Brownell \& C.G. Fairburn (Eds.), Eating disorders and obesity: A comprehensive handbook (pp. 135140). New York: Guilford.

Fairburn, C.G., Marcus, M.D., \& Wilson, G.T. (1993). Cognitive-behavioral therapy for binge eating and bulimia nervosa. In C.G. Fairburn \& G.T. Wilson (Eds.), Binge eating: Nature, assessment, and treatment (pp. 361-404). New York: Guilford.

Feldman, L.A., \& Gotlib, I.H. (1993). Social dysfunction. In C.G. Costello (ed.), Symptoms of depression (pp. 85-112). New York: Wiley.

Fielding, N. \& Fielding, J. (1986). Linking data. Newbury Park, CA: Sage.

Fielding, N. (1993). Qualitative interviewing. In N. Gilbert (Ed.), Researching social life (pp. 135-153). Newbury Park, CA: Sage.

Fohlin, (1977). Body composition, cardiovascular and renal function in adolescent patients with anorexia nervosa. Acta Paediatrica Scandinavia (suppl. 268), 1-20.

Fontana, A \& Frey, J.H. (2000). Interviewing. The art of science. In N.K. Denzin \& Y.S. Lincoln (Eds.), Collecting and interpreting qualitative materials (pp. 47-78). Newbury Park, CA: Sage

Fulkerson, J.A., Keel, P.K., Leon, G.R., \& Dorr, T. (1999). Eating-disordered behaviors and personality characteristics of high school athletes and nonathletes. International Journal of Eating Disorders, 26, 73-79.

Furnham, A., \& Greaves, N. (1994). Gender and locus of control correlates of body image dissatisfaction. European Journal of Personality, 8, 183-200.

Garner, D.M., Garfinkel, P.E., Schwartz, D., \& Thompson, M. (1980). Cultural expectations of thinness in women. Psychological Reports, 47, 483-491.

Gergen, K.J., \& Gergen, M.M. (1986). Narrative form and the construction of psychological science. In T.R. Sarbin (Ed.), Narrative psychology: The storied nature of human conduct (pp. 22-44). New York: Praeger.

Goffman, E. (1990). The presentation of self in everyday life. London: Penguin. 
Goldenbloom, D.S., \& Kennedy, S.H. (1995). Medical complications of anorexia nervosa. In K.D. Brownell \& C.G. Fairburn (Eds.), Eating disorders and obesity: A comprehensive handbook (pp. 266-270). New York: Guilford.

Goodson, I. (1988). The making of curriculum. London: Falmer Press.

Gorrell, C. (2001, September/October). Finding fault: Magazine may be abetting though not aiding an epidemic of eating disorders. Psychology Today, pp. 45-46.

Grogan, S. (1999). Body image: Understanding body dissatisfaction in men, women \& children. London: Routledge.

Hamilton, L.H., Brooks-Gunn, J., Warren, M.P., \& Hamilton, W.G. (1988). The role of selectivity in the pathogenesis of eating problems in ballet dancers. Medicine and Science in Sport and Exercise, 20, 560-565.

Harvey, J.H., Weber, A.L., \& Orbuch, T.L. (1990). Interpersonal accounts: A social psychological perspective. Oxford: Blackwell.

Hatch, J.A., \& Wisniewski, R. (1995). Life history and narrative. London: Falmer Press.

Hawkins, R.C., \& Clement, P.F. (1984). Binge eating: Measurement problems and a conceptual model. In R.C. Hawkins, W.J. Fremouw, \& P.F. Clement (Eds.), The binge-purge syndrome: Diagnosis, treatment, and research (pp. 229-251). New York: Springer.

Heatherton, T.F., \& Polivy, J. (1992). Chronic dieting and eating disorders: A spiral model. In J. Crowther, S.E. Hobfall, M.A.P. Stephens, \& D.L. Tennenbaum (Eds.), The etiology of bulimia: The individual and familial context (pp. 133-155). Washington DC: Hemisphere.

Heatherton, T.F., Nichols, P., Mahamedi, F., \& Keel, P.K. (1995). Body weight, dieting, and eating disorder symptoms among college students 1982 to 1992. American Journal of Psychiatry, 152, 1623-1629.

Hobfoll, S.E., \& Stephens, M.A.P. (1990). Social support during extreme stress: Consequences and intervention. In B.R. Sarason, I.G. Sarason, \& G.R. Pierce (Eds.), Social support: An interactional view (pp.454-481). New York: Wiley.

Hulley, A.J., \& Hill, A.J. (2001). Eating disorders and health in elite women distance runners. International Journal of Eating Disorders, 30, 312-317. 
Jourard, S.M. (1968). Disclosing man to himself. New York: Van Nostrand.

Jourard, S.M. (1971). The transparent self. New York: Van Nostrand.

King, M.B. (1989). Eating disorders in a general practice population: Prevalence, characteristics and follow-up at 12 to 18 months. Psychological Medicine Monograph Supplement, $14,1-34$.

Krasnow, M. (1996). My life as a male anorexic. London: Haworth Press.

Kvale, S. (1996). InterViews: An introduction to qualitative research interviewing. Newbury Park, CA: Sage

Laessle, R.G., Kittl, S., Fichter, M.M., Wittchen, H.H., Pirke, K.M. (1987). Major affective disorder in anorexia nervosa and bulimia: A descriptive diagnostic study. British Journal of Psychiatry, 151, 785-789.

Lazarus, R.S., \& Folkman, S. (1984). Coping and adaptation. In W.D. Gentry (Ed.), The handbook of behavioral medicine (pp. 282-325). New York: Guilford.

Leddy, M.H., Lambert, M.J., \& Ogles, B.M. (1994). Psychological consequences of athletic injury among high-level competitors. Research Quarterly for Exercise \& Sport, 65, 347-354.

Lee, C. (2004). To die for. London: Century

Leit, R.A., Pope, H.G., \& Gray, J.J. (2001). Cultural expectations of muscularity in men: The evolution of playgirl centerfolds. International Journal of Eating Disorders, 29, 90-93.

Levine, M.P., \& Smolak, L. (1992). Toward a model of the developmental psychopathology of eating disorders: The example of early adolescence. In J. Crowther, D. Tennenbaum, S. Hobfall, \& M.A.P. Stephens (Eds.), The etiology of bulimia nervosa (pp. 59-80). Washington DC: Hemisphere.

Lincoln, Y.S., \& Guba, E. (1985). Naturalistic inquiry. Beverly Hills, CA: Sage.

Maddocks, S.E., Kaplan, A.S., Woodside, D.B., Langdon, L., Piran, N. (1992). Two-year follow-up of bulimia nervosa: The importance of abstinence as the criterion of outcome. International Journal of Eating Disorders, 12, 133-141.

Manning, K. (1997). Authenticity in constuctivist: Methodological considerations without prescription. Qualitative Inquiry, 3, 93-115.

Marcia, J.E. (1966). Development and validation of ego identity status. Journal of Personality 
and Social Psychology, 3, 551-558.

Marlatt, G.A. (1985). Relapse prevention: Theoretical rationale and overview of the model. In G.A. Marlatt \& J.R. Gordon (Eds.), Relapse prevention: Maintenance strategies in the treatment of addictive behaviors (pp. 3-70). New York: Guilford Press.

Marlatt, G.A. (1995). Relapse: A cognitive-behavioral model. In K.D. Brownell \& C.G.

Fairburn (Eds.), Eating disorders and obesity: A comprehensive handbook (pp. 541546). New York: Guilford.

Maruna, S. (1997). Going straight: Desistance from crime and life narratives of reform. In R. Josselson \& A. Lieblich (Eds.), The narrative study of lives (Vol. 5). Newbury Park, CA: Sage.

Mason, J. (2002). Qualitative researching. Newbury Park, CA: Sage.

McAdams, D.P. \& Bowman, P.J. (2002). Narrating life’s turning points: Redemption and contamination. In D.P. McAdams, R. Josselson, \& A. Lieblich (Eds.), Turns in the road: Narrative studies of lives in transition (pp. 3-34). Washington DC: American Psychological Association.

Mitchell, J.E. (1995). Medical complications of bulimia nervosa. In K.D. Brownell \& C.G. Fairburn (Eds.), Eating disorders and obesity: A comprehensive handbook (pp. 271275). New York: Guilford.

Mitchell, J.E., Pyle, R.L., Hatsukami, D., Goff, G., Glotter, D., \& Harper, J. (1988). A 2-5 year follow-up to study of patients treated for bulimia. International Journal of Eating Disorders, 8, 157-165.

Newman, B.M., \& Lohman, B.J., Newman, P.R., Myers, M.C., \& Smith, V.L. (2000). Experiences of urban youth navigating the transition to ninth grade. Youth \& Society, 31, 387-416.

Newman, B.M., \& Newman, P.R. (2001). Group identity and alienation: Giving the we its due. Journal of Youth and Adolescence, 30, 515-538.

Noden, M (1994, August 8). Dying to win. Sports Illustrated, 81(6), 52-60.

Oakley, A. (1981). Interviewing women: A contradiction in terms. In H. Roberts (Ed.), Doing femininity research (pp. 30-61). London: Routledge.

Olivardia, R., Pope, H.G., Mangweth, B., \& Hudson, J.I. (1995). Eating disorders in college 
men. American Journal of Psychiatry, 152, 1279-1285.

Page R.M., \& Allen, O. (1995). Adolescent perceptions of body weight and weight satisfaction. Perceptual and Motor Skills, 81, 81-83.

Pancer, S.M., Hunsberger, B., Pratt, M.W., \& Alisat, S. (2000). Cognitive complexity of expectations and adjustment to university in the first year. Journal of Adolescent Research, 15, 38-57.

Paykel, E.S., \& Cooper, Z. (1992). Life events and social stress. In E.S. Paykel (Ed.), Handbook of affective disorders (2nd ed., pp 149-170). London: Guilford.

Petrie, T.A. (1996). Differences between male and female college lean sport athletes, nonlean sport athletes, and nonathletes on behavioral and psychological indices of eating disorders. Journal of Applied Sport Psychology, 8, 218-230.

Petrie, T. A., \& Sherman, R. T. (2000). Counseling athletes with eating disorders: A case example. In M. B. Andersen (Ed.), Doing sport psychology (pp. 121-137). Champaign, IL: Human Kinetics.

Piran, N., Levine, M.P., \& Steiner-Adair, C. (Eds.). (1999). Preventing eating disorders: A handbook of interventions and special challenges. Philadelphia: Brunner/Mazel.

Raudenbush, B., \& Zellner, D. (1997). Nobody’s satisfied: Effects of abnormal eating behaviors and actual and perceived weight status on body image satisfaction in males and females. Journal of Social and Clinical Psychology, 16, 95-110.

Ricks, D.F. (1974). Life history research: Retrospect and prospect 1973. In D.F. Ricks, A. Thomas, \& M. Roff (Eds.), Life history research in psychopathology (pp. 350-370). Minneapolis: University of Minnesota Press.

Ricks, D.F., Thomas, A., Roff, M. (1974). Preface. In D.F. Ricks, A. Thomas, \& M. Roff (Eds.), Life history research in psychopathology (pp. vii-x). Minneapolis: University of Minnesota Press.

Rigotti, N.A., Neer, R.M., Skates, S.J., Herzog, D.B., \& Nussbaum, S. (1991). The clinical course of osteoporosis in anorexia nervosa: A longitudinal study of cortical bone mass. Journal of the American Medical Association, 265, 1133-1138.

Rosenthal, R., \& Jacobson, L. (1992). Pygmalion in the classroom: Teacher expectations and pupils’ intellectual development. New York: Irvington. 
Rubin, L.B. (1985). Just friends: The role of friendship in our lives. New York: Harper \& Row. Russell, G.M.F. (1970). Anorexia nervosa: Its identity as an illness and its treatment. In J.H. Price (Ed.), Modern trends in psychological medicine (Vol. 2, pp. 131-164). London: Butterworths.

Ryan, J. (1996). Little girls in pretty boxes: The making and breaking of elite gymnasts and figure skaters. New York: Warner.

Schlossberg, N. (1981). A model for analyzing human adaptation to transition. Counseling Psychologist, 9, 2-18.

Schmidt, U.H., Tiller, J.M., Andrews, B., Blanchard, M., \& Treasure, J.L. (1997). Is there a specific trauma precipitating onset of anorexia nervosa? Psychological Medicine, 27, 523-530.

Seligman, M.E.P. (1992). Helplessness: On development, depression and death. New York: W.H. Freeman and Company.

Sharp, C.W., \& Freeman, C.P.L. (1993). The medical complications of anorexia nervosa. British Journal of Psychiatry, 162, 452-462.

Sherman, R.T., \& Thompson, R.A. (2001). Athletes and disordered eating: Four major issues for the professional psychologist. Professional Psychology: Research and Practice, 32, 27-33.

Simmons, M.S., Grayden, S.K., \& Mitchell, J.E. (1986). The need for psychiatric-dental liaison in the treatment of bulimia. American Journal of Psychiatry, 143, 783-784.

Smith, J.L. (August 8, 2004). 'I hated people being thinner than me'. The Sunday Telegraph Magazine, 28-33.

Smolak, L., Murnen, S.K., \& Ruble, A.E. (2000). Female athletes and eating problems: A metaanalysis. International Journal of Eating Disorders, 27, 371-380.

Sparkes, A.C., Schempp, P.G., \& Templin, T.J. (1993). Exploring dimensions of marginality: Reflecting on life histories of physical education teachers. Journal of Teaching in Physical Education, 12, 386-398.

Stillwell, A. M., \& Baumeister, R. F. (1997). The construction of victim and perpetrator memories: Accuracy and distortion in role-based accounts. Personality and Social Psychology Bulletin, 23, 1157-1172. 
Striegal-Moore, R.H. (1993). Etiology of binge eating: A developmental perspective. In C.G. Fairburn \& G.T. Wilson (Eds.), Binge eating: Nature, assessment, and treatment (pp. 144-172). New York: Guilford.

Striegal-Moore, R.H., Silberstein, L.R., \& Rodin, J. (1986). Toward an understanding of risk factors for bulimia. American Psychologist, 41, 246-263.

Sullivan, P.F. (1995). Mortality in anorexia nervosa. American Journal of Psychiatry, 152, 1073-1074.

Sundgot-Borgen, J. (1994). Eating disorders in female athletes. Sports Medicine, 17, 176-188. Swift, W.J., Andrews, D., \& Barklage, N.E. (1986). The relationship between affective disorders and eating disorders: A review of the literature. American Journal of Psychiatry, 143, 290-299.

Szmukler, G., Dare, C., \& Treasure, J. (Eds.). (1995). Handbook of eating disorders: Theory, treatment and research. Chichester: Wiley.

Taylor, J. \& Ogilvie, B. (2001). Career termination among athletes. In R.N. Singer, H.A. Hausenblas, \& C.M. Janelle (Eds.), Handbook of sport psychology (2nd ed., pp. 672691). New York: John Wiley.

Thompson, R.A. \& Sherman, R.T. (1993). Helping athletes with eating disorders. Champaign IL: Human Kinetics.

Thompson, R.A. \& Sherman, R.T. (1999). “Good athlete” traits and characteristics of anorexia nervosa: Are they similar? Eating Disorders: The Journal of Treatment and Prevention, 7, 181-190.

Tierney, W.G. (2000). Undaunted courage: Life history and the postmodern challenge. In N.K. Denzin \& Y.S. Lincoln (Eds.), Handbook of qualitative research ( $2^{\text {nd }}$ ed.; pp. 537553). Newbury Park, CA: Sage.

Tillmann-Healey, L.M. (2001). Between gay and straight: Understanding friendship across sexual orientation. Walnut Creek, CA: AltaMira Press.

Tillmann-Healey, L.M. (2003). Friendship as method. Qualitative Inquiry, 9, 729-749.

Vitousek, K., \& Manke, F. (1994). Personality variables and disorders in anorexia nervosa and bulimia nervosa. Journal of Abnormal Psychology, 103, 137-147.

Vohs, K.D., Heatherton, T.F., \& Herrin, M. (2001). Disordered eating and the transition to 
college: A prospective study. International Journal of Eating Disorders, 29, 280-288.

Wazeter, M., \& Lewis, G. (1989). Dark marathon: The Mary Wazeter story. Grand Rapids, MI: Zondervan.

Wilson, G.T. (1993). Relation of dieting and voluntary weight loss to psychological functioning and binge eating. Annals of Internal Medicine, 119, 727-730.

Zeidner, M., \& Saklofske, D. (1996). Adaptive and maladaptive coping. In M. Zeidner \& N.S. Endler (Eds.), Handbook of coping: Theory, research, applications (pp. 505-531). New York: John Wiley \& Sons.

Ziegler, P.J., Khoo, C.S., Sherr, B., Nelson, J.A., Larson, W.M. \& Drewnowski, A. (1998). Body image and dieting behaviors among elite figure skaters. International Journal of Eating Disorders, 24, 421-427. 